\title{
A Self-assembling Nanomaterial Reduces Acute Brain Injury and Enhances Functional Recovery in a Rat Model of Hypertensive Intracerebral Hemorrhage
}

\author{
Lynn Yan-Hua Sang ${ }^{1,2,7}$, Yu-Xiang Liang ${ }^{3,7}$, Kwok-Fai So ${ }^{3,4,7,8}$, Gilberto Ka-Kit Leung ${ }^{1,7}$, Rutledge G Ellis-Behnke ${ }^{5,6,7}$ and Raymond Tak-Fai \\ Cheung ${ }^{2,4 *}$ \\ ${ }^{1}$ Department of Surgery, Li Ka Shing Faculty of Medicine, University of Hong Kong, Hong Kong, China \\ ${ }^{2}$ Department of Medicine, Li Ka Shing Faculty of Medicine, University of Hong Kong, Hong Kong, China \\ ${ }^{3}$ State Key Lab of Brain and Cognitive Sciences, University of Hong Kong, Hong Kong, China \\ ${ }^{4}$ Research Centre of Heart, Brain, Hormone and Healthy Aging, Li Ka Shing Faculty of Medicine, University of Hong Kong, Hong Kong, China \\ ${ }^{5}$ Department of Brain and Cognitive Sciences, Massachusetts Institute of Technology, Cambridge, Massachusetts, USA \\ ${ }^{6}$ Department of Ophthalmology, Medical Faculty Mannheim, Ruprecht-Karls-University, Heidelberg, Germany \\ ${ }^{7}$ Department of Anatomy, Li Ka Shing Faculty of Medicine, University of Hong Kong, Hong Kong, China \\ ${ }^{8}$ Department of Ophthalmology, Li Ka Shing Faculty of Medicine, University of Hong Kong, Hong Kong, China
}

\begin{abstract}
Intracerebral hemorrhage $(\mathrm{ICH})$ carries a high morbidity and mortality rate. High systolic blood pressure promotes hematoma growth. A self-assembling peptide (SAP) can achieve immediate hemostasis via formation of a SAP nanofiber scaffold (SAPNS). A minimally invasive aspiration of hematoma plus local delivery of SAPNS may lead to decompression of brain tissue and prevent hematoma growth.

In a rat model of renovascular hypertension, experimental $\mathrm{ICH}$ was induced by a local injection of bacterial collagenase IV into the left basal ganglia. At 3.5 hours after induction of $\mathrm{ICH}$, stereotactic clot aspiration or sham aspiration was performed manually. Following hematoma aspiration, an intrastriatal injection of $1 \%$ SAP, saline or sham injection was performed. Hematoma volume and brain swelling were quantified at 24 hours after $\mathrm{ICH}$. Brain sections were immuno histochemically processed for myeloperoxidase and CD68 to detect the inflammatory infiltration in the perihematomal area. Perihematomal apoptotic cell death was determined using TUNEL staining. Functional recovery was assessed using neurological severity score and modified limb placement test at 1, 3, 7, 10 days after ICH.

The combined treatment with hematoma removal and locally delivered SAPNS decreased hematoma volume, hematoma growth, brain edema, perihematomal inflammatory cell infiltration and apoptosis, as well as improved sensorimotor functional recovery.

Locally delivered SAPNS after hematoma aspiration may prevent hematoma growth, facilitate the repair of $\mathrm{ICH}-$ related brain injury and promote functional recovery. Such combined treatment may be effective in patients with hypertensive $\mathrm{ICH}$.
\end{abstract}

Keywords: In vivo; Intracerebral hemorrhage; Nanomaterial; Rat; Hypertension; Self-assembling peptide nanofiber scaffold

\section{Introduction}

Intracerebral hemorrhage (ICH) is a more deadly type of stroke, and neurological disability is common among survivors [1]. Hypertension is the main cause of spontaneous ICH. The International Society of Hypertension (ISH) states that high blood pressure (BP; >140/90 mm $\mathrm{Hg}$ ) occurs in $>80 \%$ of ICH patients and is independently associated with a poor functional outcome $[2,3]$. Mechanisms of ICH-related brain injury in hypertensive patients need to be elucidated. Hematoma growth is consistently associated with increased mortality and poor clinical outcome [4-7]. Therefore, stopping hematoma growth is an important treatment strategy to improve the survival rate and outcome after ICH. Systemically delivered hemostatic therapies can stop bleeding, but both systemic and cerebral circulation may be compromised. Therefore, stereotactic minimal invasive aspiration combined with local delivery of a hemostatic material seems promising, especially in the ultra-early phase. In this study, a rat model of hypertensive ICH was used to investigate the effects of combined mechanical removal of hematoma and local delivery of a nanomaterial on brain injury and functional recovery.

RADA16-I (Ac-RADARADARADARADA-CONH ${ }_{2} \mathrm{R}$, arginine; $\mathrm{A}$, alanine; $\mathrm{D}$, aspartate) is a self-assembling peptide (SAP). It contains regular repeats of ionic hydrophilic and hydrophobic amino acids which are chemically synthesized and form extremely stable $\beta$-sheet structures in water. Thousands of peptides self-assemble to form a single nanofiber, and trillions of peptides or billions of nanofibers form the scaffold that contains $\approx 99.5 \%$ water and $0.5 \%$ peptide materials. The gelation process is charge dependent and accelerated either by changing to a neutral $\mathrm{pH}$ or by contacting physiological concentration of salt solutions. The scanning electron microscopy (SEM) image shows the scaffold after the assembly of all of the polypeptides (Figure 1). This peptide can form stable $\beta$-sheet structures and eventually turn into a hydrogel [8]. Previous studies in a hamster midbrain severed optical

*Corresponding author: Raymond Tak-Fai Cheung, Department of Medicine University of Hong Kong, Administration Block, Queen Mary Hospital, Pokfulam, Hong Kong, China, Tel: 852-22554049; Fax: 852-28186474; E-mail: rtcheung@hku.hk

Received July 25, 2014; Accepted August 20, 2014; Published August 27, 2014

Citation: Sang LY, Liang YX, So KF, Leung GK, Ellis-Behnke RG, et al. (2014) A Self-assembling Nanomaterial Reduces Acute Brain Injury and Enhances Functional Recovery in a Rat Model of Hypertensive Intracerebral Hemorrhage. J Nanomed Nanotechnol 5: 224. doi: 10.4172/2157-7439.1000224

Copyright: (C) 2014 Sang LY, et al. This is an open-access article distributed under the terms of the Creative Commons Attribution License, which permits unrestricted use, distribution, and reproduction in any medium, provided the original author and source are credited. 
Citation: Sang LY, Liang YX, So KF, Leung GK, Ellis-Behnke RG, et al. (2014) A Self-assembling Nanomaterial Reduces Acute Brain Injury and Enhances Functional Recovery in a Rat Model of Hypertensive Intracerebral Hemorrhage. J Nanomed Nanotechnol 5: 224. doi: 10.4172/2157-7439.1000224

Page 2 of 7

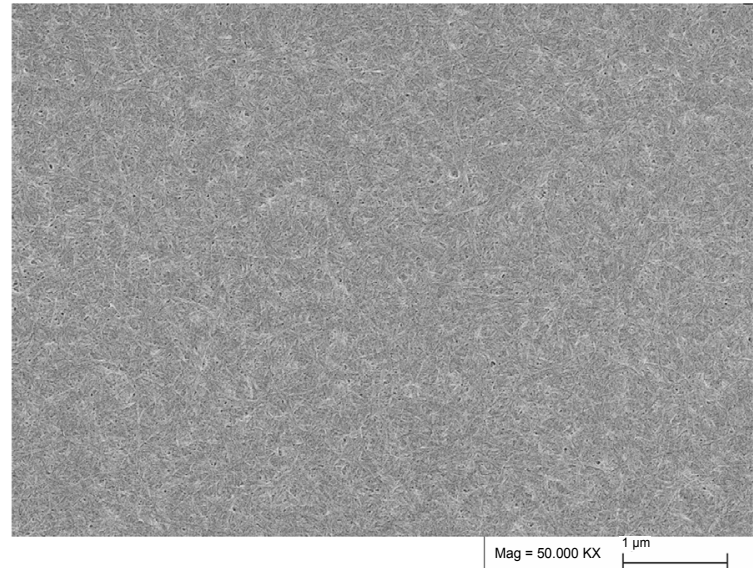

Figure 1: The SEM image showing the scaffold after the assembly of RADA16-I peptides.

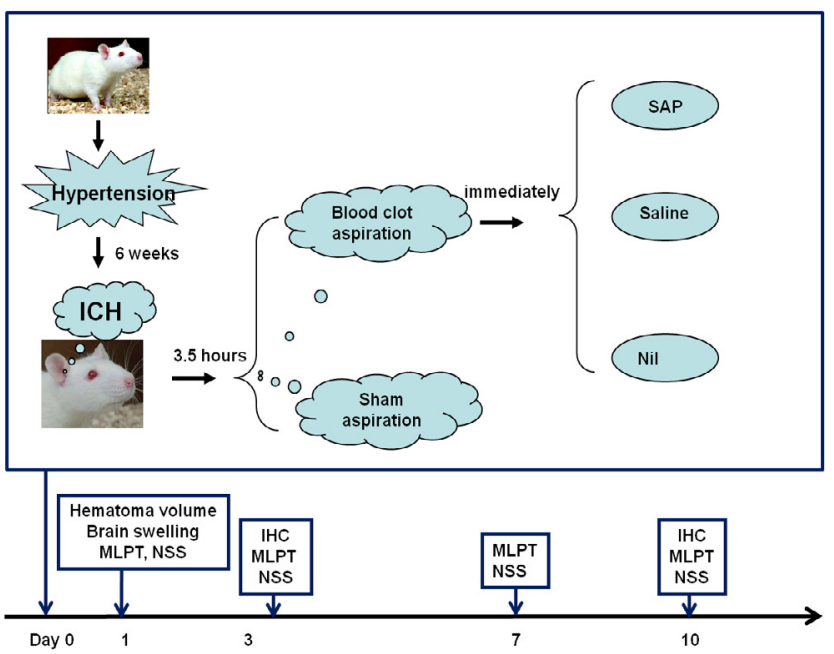

Figure 2: Experimental schedule to investigate the effect of a locally delivered nanomaterial on brain injury and recovery in $\mathrm{ICH}$.

tract model have shown that injection of this SAP solution into the incision would lead to regeneration of the optic tract and functional recovery of vision [9]. In vivo study has shown that this peptide-based nanofiber scaffold could offer a permissive environment for axon regeneration and accelerate wound healing [8]. Our previous study showed that RADA16-I scaffold could reduce the post-ICH cerebral inflammation, apoptosis, and promote long-term functional recovery in a normotensive animal model [10]. However, it is unknown whether this scaffold would affect ICH-related brain injury in hypertensive animals. Interestingly, this nanomaterial has been found to stop bleeding at surgical sites [11]. It is possible that RADA16-I scaffold can act as a nanobarrier and prevent rebleeding when applied to the lesion cavity after hematoma aspiration.

To establish a hypertensive animal model, the normotensive SD rats were subjected to left renal artery constriction to induce renovascular hypertension (RVHT) [12]. Animals with elevated BP were used to establish an ICH plus ultra-early hematoma aspiration model. Collagenase injection was used to achieve a reproducible hematoma and permit hematoma growth. Stereotactic hematoma aspiration may result in significant reduction in the hematoma volume and offer a reasonable space for administration of the SAP solution or normal saline. Hematoma volume and brain swelling 24 hours after ICH were assessed, and brain sections were processed for immunohistochemistry (IHC) to assess apoptosis and inflammation. Functional recovery was assessed using modified limb placement test (MLPT) and neurological severity score (NSS). Our findings showed that the RADA16-I scaffold replaced the brain hematoma, prevented hematoma growth, reduced acute brain injury, and improved functional recovery.

\section{Methods}

Experimental protocols were approved by the Committee on the Use of Live Animals in Teaching and Research, the University of Hong Kong. Male Sprague-Dawley rats, 6-8 weeks old and weighing 260-280 g, were used in this study. Animals were kept on a 12 / 12 light / dark cycle with ad libitum access to food and water. The animal holding areas were under constant monitoring, and the temperature was kept at $23 \pm$ $2^{\circ} \mathrm{C}$.

RVHT was induced by applying a silver clip to the left renal artery [13]. Six weeks after renal artery constriction, hypertensive rats were randomly assigned to one of the four groups: the ICH only group, with induction of $\mathrm{ICH}$ and sham hematoma aspiration; the aspiration only (Asp) group, with induction of $\mathrm{ICH}$ and subsequent hematoma aspiration; the saline group, with induction of $\mathrm{ICH}$, hematoma aspiration, and intralesional injection of saline; and the SAP group, with induction of $\mathrm{ICH}$, hematoma aspiration, and intralesional injection of the SAP solution. The experimental procedures are summarized in Figure 2 .

The first cohort of rats ( $n=4-6$ per group, a total of 19 rats) were sacrificed 1 day after ICH for the assessment of hematoma volume and brain swelling. The second cohort of rats ( $\mathrm{n}=4$ per group, a total of 16 rats) were sacrificed 3 days after ICH for assessment of perihematomal infiltration of neutrophils and apoptosis. The third cohort of rats $(\mathrm{n}=$ 21) were sacrificed 10 days after ICH for the evaluation of infiltration of microglia/macrophages and functional assessment. The latter was also performed on day 1,3 , and 7 after ICH.

\section{RVHT model and BP measurement}

RVHT was induced by applying a solid silver clip onto the left renal artery (2K1C model), leaving the contralateral artery undisturbed $[14,15]$. In brief, 6 to 8 week-old male rats were anesthetized with an intraperitoneal injection of ketamine $(67 \mathrm{mg} / \mathrm{kg})$ and xylazine $(6 \mathrm{mg} /$ $\mathrm{kg}$ ). After anesthesia, a $3-\mathrm{cm}$ median longitudinal skin incision was made in the abdomen. The left renal artery was stretched and separated from the left renal vein. A silver clip with an inner diameter of 0.25 $\mathrm{mm}$ was applied onto the exposed left renal artery as close to the aorta as possible. Systolic BP (SBP) was measured weekly after the unilateral renal artery constriction using an indirect tail-cuff method as described previously [16]. Rats were observed for $10 \mathrm{~min}$ daily to assess their general behavior, including grooming and exploratory activities, level of alertness, and physical well-being. Rats with SBP $>150 \mathrm{mmHg}$ at 6 weeks after the renal artery constriction were regarded as RVHT rats and used in subsequent ICH study.

\section{Hematoma aspiration with or without intralesional injection after ICH}

Experimental ICH was induced via an intrastriatal injection of type IV collagenase $[17,18]$. In brief, a burr hole of $2 \mathrm{~mm}$ diameter was drilled along the left coronal suture at $3.0 \mathrm{~mm}$ lateral to the bregma. 
Citation: Sang LY, Liang YX, So KF, Leung GK, Ellis-Behnke RG, et al. (2014) A Self-assembling Nanomaterial Reduces Acute Brain Injury and Enhances Functional Recovery in a Rat Model of Hypertensive Intracerebral Hemorrhage. J Nanomed Nanotechnol 5: 224. doi: 10.4172/2157-7439.1000224

Page 3 of 7

A 30-gauge (G) needle was inserted into the left striatum with its tip at $0.2 \mathrm{~mm}$ anterior to the bregma, $3 \mathrm{~mm}$ lateral to the midline and 6 $\mathrm{mm}$ underneath the dural surface. ICH was induced by a slow injection of 0.12 units collagenase IV (Sigma-Aldrich, St. Louis, USA) in 1.0 $\mu \mathrm{L}$ saline into the left striatum over $10 \mathrm{~min}$. Three and a half hours after collagenase injection, aspiration was achieved by gentle suction through a $1 \mathrm{~mL}$ syringe attached to a $23-\mathrm{G}$ needle. The needle was placed at the same stereotactic coordinates as the collagenase injection. Four aspirations were performed over $15 \mathrm{~min}$. Following aspiration, 20 $\mu \mathrm{L}$ of $1 \%$ RADA16-I solution or saline was injected into the lesion via a $25-\mathrm{G}$ needle. The rate of infusion was $500 \mu \mathrm{L}$ per hour. Finally, the burr hole was sealed with bone wax, and the wound was sutured. In the ICH only group, a 23-G needle was placed at the hematoma center for 4 attempts over $15 \mathrm{~min}$, but aspiration was not done.

\section{Hematoma volume and brain swelling}

Hematoma volume and brain swelling were quantified 24 hours after ICH. In brief, the rats were transcardially perfused with normal saline followed by $50 \mathrm{ml}$ of $4 \%$ paraformaldehyde in $0.1 \mathrm{M}$ phosphate buffer (PB). The brain tissue was sliced into eight $1 \mathrm{~mm}$-thick coronal slices using an adult rat brain matrix (World Precision Instruments, Inc., Sarasota, FL). Images of the tissue slices were taken using a digital camera and analyzed using Image J software (NIH, USA) by an observer blinded to group identity. Hematoma volume was calculated by summing the lesion area on each slice and multiplied by the slice thickness. Hemispheric brain swelling after ICH was calculated as the increased volume of ipsilateral hemisphere with respect to the volume of contralateral hemisphere. Data were presented as the percentage increase in brain swelling and expressed as (ipsilateral volume excluding ventricle - contralateral volume excluding ventricle) / contralateral volume $\times 100 \%[19]$.

\section{Immunohistochemical analyses}

The rat was perfused transcardially with ice-cold saline and then $4 \%$ paraformaldehyde in $0.1 \mathrm{M} \mathrm{PB}$ for $20 \mathrm{~min}$. The brain was post fixed in $4 \%$ paraformaldehyde overnight at $4^{\circ} \mathrm{C}$ before placed in $30 \%$ sucrose containing $0.1 \mathrm{M} \mathrm{PB}$ for 4 days. Brain sections at $30 \mu \mathrm{m}$ were obtained between $1 \mathrm{~mm}$ anterior to the bregma and $2 \mathrm{~mm}$ posterior to the bregma using a cryostat at $-18^{\circ} \mathrm{C}$. Brain sections were affixed on Superfrost Plus slides (Menzel-Glaser, Braunschweig, LS, Germany) and air-dried overnight.

After washing, the brain sections were incubated in non-specific blocking solution ( $10 \%$ goat serum) for 1 hour at room temperature. The slides were then incubated with the primary antibody at $4^{\circ} \mathrm{C}$ overnight. Neutrophils were detected with the rabbit anti-MPO antibody (1:200; Dako, Glostrup, Denmark); microglia/macrophages were identified using mouse anti-ED-1 antibody (1:200; Serotec, Kidlington, UK). After the primary antibody incubation, the sections were washed 3 times in phosphate buffered saline (PBS) for $10 \mathrm{~min}$ each time. The sections were incubated with the biotinylated goat anti-rabbit or goat anti-mouse secondary antibody for 2 hours at room temperature and followed by washing in PBS. To amplify the signals, an avidin-biotin complex solution (1:200; Vector, Burlingame, USA) was used. After $30 \mathrm{~min}$, sections were washed in PBS, and the signal was visualized by 3, 3'-diaminobenzidine (DAB; Vector, Burlingame, CA, USA) for detection of the peroxidase signal. Sections were then cover slipped for examination under a light microscope.

Apoptosis was assessed by terminal deoxynucleotidyl transferased UTP nick end labeling (TUNEL) assay with an in situ cell death detection kit (Roche, Indianapolis, IN) [20-23]. The fixed brain sections were blocked with $3 \% \mathrm{H}_{2} \mathrm{O}_{2}$ in methanol to quench the endogenous peroxidase. The sections were incubated in the permeabilization solution and then incubated in labeling reaction mixture for $60 \mathrm{~min}$ at $37^{\circ} \mathrm{C}$ in the dark. After incubating in converter-POD for $30 \mathrm{~min}$ at $37^{\circ} \mathrm{C}$, sections were stained with $\mathrm{DAB}-\mathrm{H}_{2} \mathrm{O}_{2}$. The slides were examined under a light microscope.

The cell quantification process was conducted in a blinded manner. The number of positive cells in the perihematomal area was counted. The total number of positive cells within these brain sections was converted to cell density to facilitate comparison among the groups.

\section{Functional deficits}

Functional deficits were assessed on day 1, 3, 7, and 10 after ICH. The rats were subjected to MLPT and NSS by a blinded observer [24]. MLPT consists of 3 limb-placement tasks that assess the sensorimotor integration of the forelimb and the hind limb by checking responses to tactile and proprioceptive stimulation [24]. First, the rat was suspended at $10 \mathrm{~cm}$ above a table, and the stretch of the forelimbs toward the table was scored as follows: 0 point for normal stretch and 1 point for abnormal flexion. Next, the rat was positioned along the table edge, and its forelimbs were suspended over the edge and allowed to move freely. Each limb (forelimb, second task; hind limb, third task) was pulled down gently, and the retrieval and placement were checked. Finally, the rat was placed toward the table edge to check for lateral placement of the forelimbs. The last three tasks were scored in the following manner: 0 point for normal performance, 1 point for performance with a delay $(2$ seconds) or incomplete performance, and 2 points for no performance. A score of seven points indicates maximal neurological deficit, and a score of 0 point indicates normal performance.

Modified NSS was adopted from previous reports with some modification $[25,26]$. NSS is a composite of motor, sensory, reflex, and balance tests. Points were awarded for the inability to perform the test or for the lack of a tested reflex; thus, the higher score, the more severe is the injury [10]. All animals were trained to be familiar with the testing environment before ICH surgery.

\section{Statistical analysis}

Statistical analyses were performed using the Graph Pad Prism (version 5, San Diego, CA, USA). Group differences were assessed by ANOVA followed by LSD post-hoc test. For the longitudinal functional assessment, two-way analysis of variance was used. Kruskal-Wallis ANOVA on ranks followed by Mann-Whitney U post hoc test was used for data not in normal distribution. Statistical difference was inferred by a $P$ value less than 0.05 . Values were in mean $\pm S D$.

\section{Results}

\section{Hematoma volume}

In RVHT rats, the hematoma volume was not significantly reduced by aspiration (Figure 3). A significant reduction of hematoma volume was found in the SAP group $(6.57 \pm 5.19 \mu \mathrm{L})$ when compared to the other groups (Figure 3 ). There were no significant differences in hematoma volume among the ICH only group $(32.11 \pm 11.70 \mu \mathrm{L})$, the Asp group $(29.19 \pm 9.53 \mu \mathrm{L})$ and the saline group $(30.49 \pm 12.63 \mu \mathrm{L})$.

\section{Brain swelling}

Ipsilateral hemisphere showed greater brain swelling than the contralateral hemisphere 24 hours after ICH in all groups (Figure $3 \mathrm{C}$ ). However, brain swelling was significantly reduced in the ipsilateral hemisphere of the SAP group $(8.80 \pm 3.55 \%)$ relative to that in ICH only 
Citation: Sang LY, Liang YX, So KF, Leung GK, Ellis-Behnke RG, et al. (2014) A Self-assembling Nanomaterial Reduces Acute Brain Injury and Enhances Functional Recovery in a Rat Model of Hypertensive Intracerebral Hemorrhage. J Nanomed Nanotechnol 5: 224. doi: $10.4172 / 2157-7439.1000224$

Page 4 of 7

A

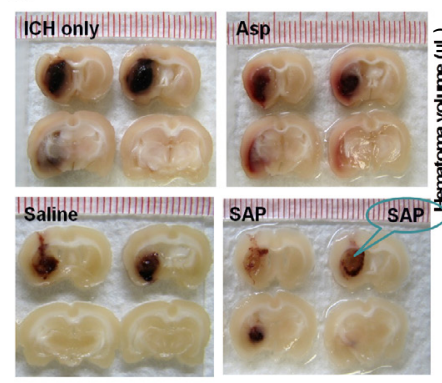

B

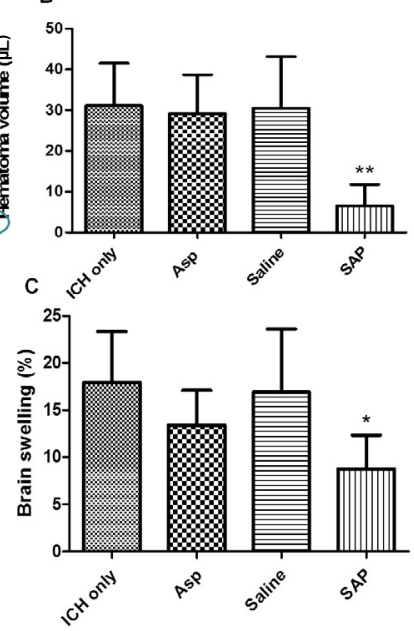

Figure 3: (A) Representative images show brain injury 1 day after $\mathrm{ICH}$. (B) Hematoma volume 24 hours after $\mathrm{ICH}{ }^{* *} \mathrm{P}<0.01$ versus the other three groups. (C) Brain swelling 1 day after $\mathrm{ICH}$. ${ }^{*} \mathrm{P}<0.05$ versus the $\mathrm{ICH}$ only group. $n=5$ for the ICH only group, $n=4$ for the Asp group, $n=4$ for the saline group, and $n=6$ for the SAP group. Asp: aspiration only.

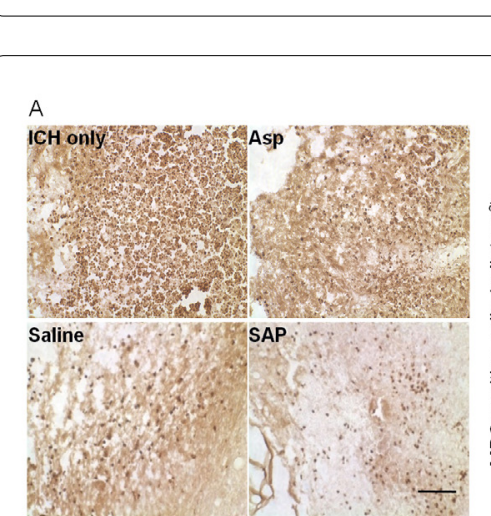

\section{B}

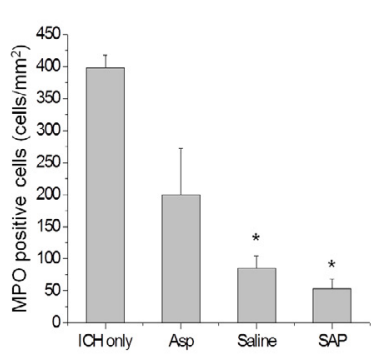

Figure 4: Neutrophil infiltration 3 days after $\mathrm{ICH}$. (A) Representative images showed MPO positive cells in the perihematomal area. (B) Quantitative analysis of MPO positive cells at the edge of the hematoma in cells $/ \mathrm{mm}^{2} . \mathrm{n}=$ 4 per group. ${ }^{*} \mathrm{P}<0.05$ versus the $\mathrm{ICH}$ only group. Asp: Scale bar $=100 \mu \mathrm{m}$. aspiration only.

group (17.96 $\pm 5.39 \%$, Figure 3C). The SAP group also demonstrated a trend of less brain swelling than the Asp group and the saline group, but statistical significance was not reached. Brain swelling in the Asp group $(13.40 \pm 3.71 \%)$ and the saline group $(16.90 \pm 6.71 \%)$ was not different from that in the ICH only group.

\section{Cerebral inflammation}

MPO immunoreactivity revealed a high density of positive cells within the hematoma and in the perihematomal area in the ICH only group $\left(394.6 \pm 24.2\right.$ cells per $\left.\mathrm{mm}^{2}\right) 3$ days after ICH (Figure $4 \mathrm{~A}$ ). However, aspiration only $\left(195.4 \pm 68.5\right.$ cells per $\left.\mathrm{mm}^{2}\right)$ did not significantly reduce the number of MPO immuno-positive cells. Additional local injection of saline $\left(72.2 \pm 23.6\right.$ cells per $\left.\mathrm{mm}^{2}\right)$ or SAPNS $(53.8 \pm 19.16$ cells per $\mathrm{mm}^{2}$ ) significantly reduced the neutrophil infiltration versus the ICH only group (Figure 4B). Moreover, the SAP group tended to further reduce the MPO immune-positive neutrophil counts in perihematomal area.

ED-1 immuno-positive cells had an amoeboid or round phagocytic

morphology and were found in the perihematomal area and within the hematoma in all groups 10 days after $\mathrm{ICH}$ (Figure 5). The perihematomal ED-1 immuno-positive cell densities were similar among the ICH only group $\left(127.8 \pm 28.1\right.$ cells per $\left.\mathrm{mm}^{2}\right)$, the Asp group $(93.6 \pm 17.6$ cells per $\left.\mathrm{mm}^{2}\right)$ and the saline group $\left(90.3 \pm 11.2\right.$ cells per $\left.\mathrm{mm}^{2}\right)$. Treatment with SAPNS reduced the number of ED-1 immuno-positive cells (40.1 \pm 5.0 cells per $\mathrm{mm}^{2}$ ) when compared to other three groups (Figure $5 \mathrm{C}$ ). In the lesion core, there were very few ED-1 immuno-positive cells infiltrating the SAPNS in the SAP group, while there was a high density of ED-1 immuno-positive cells in the ICH only group, the Asp group and the saline group (Figure 5B).

\section{Apoptosis}

Three days after ICH, TUNEL revealed a high density of positively labeled cells within the hematoma and in the perihematomal area in the ICH only group $\left(100.9 \pm 15.1\right.$ cells per $\mathrm{mm}^{2}$; Figure 6$)$. The results were similar in the Asp group $\left(55.5 \pm 5.4\right.$ cells per $\left.\mathrm{mm}^{2}\right)$ and the saline group (44.4 \pm 19.8 cells per $\mathrm{mm}^{2}$; Figure 6$)$ and not significantly different from the ICH only group (Figure 6B). Treatment with the SAP reduced the number of TUNEL-labeled cells $\left(21.2 \pm 3.8\right.$ cells per $\left.\mathrm{mm}^{2}\right)$ when compared to the other groups.

\section{Functional deficits}

All rats survived after the surgery and completed the behavioral tests. MLPT deficits were maximal at 1 week after $\mathrm{ICH}$ and showed a trend of recovery within the first 10 days. A significant sensorimotor functional improvement $(4.0 \pm 0.5)$ was detected in the SAP group 10 days after ICH (Figure 7A) when compared to the other three groups, viz. the ICH only $(5.4 \pm 0.5)$, the Asp group $(5.5 \pm 1.0)$, and the saline group $(6.1 \pm 0.5)$. According to the NSS, the SAP group exhibited a slightly better performance than the other groups 3 days after ICH (Figure 7B), and the difference became statistically significant 7 days (the SAP group, $7.6 \pm 1.3$; the ICH only, $9.7 \pm 0.8$; the Asp, $10.2 \pm 0.9$; and the saline group, $9.9 \pm 1.3$ ) and 10 days after ICH (the SAP group, $6.4 \pm 1.0$; the ICH only, $8.8 \pm 0.7$; the Asp, $9.6 \pm 1.7$; and the saline

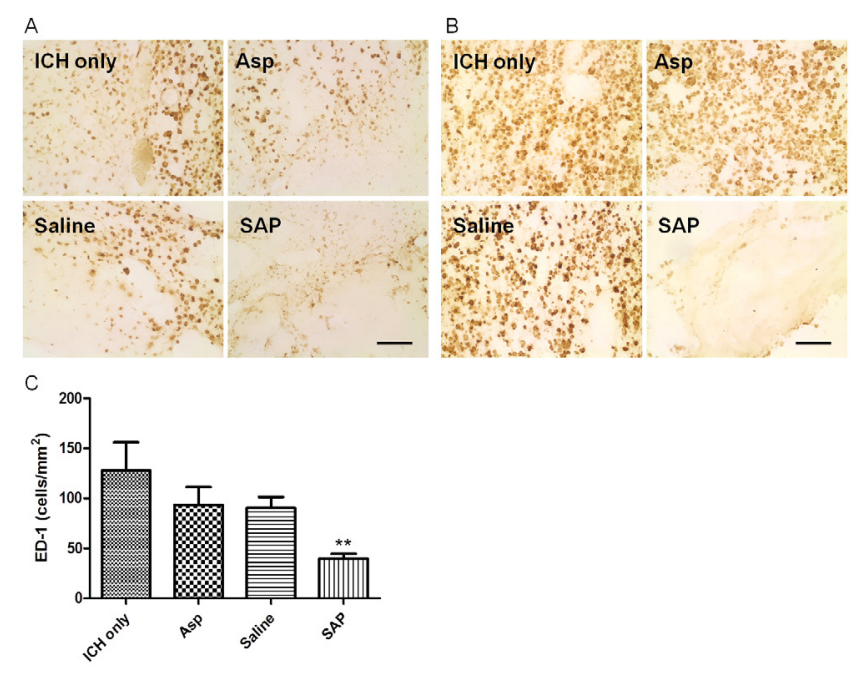

Figure 5: Microglia/macrophage activation 10 days after $\mathrm{ICH}$. (A) Representative images showed ED-1 positive cells at the edge of hematoma. (B) Representative images showed ED-1 positive cells in the lesion core. Scale bar $=100 \mu \mathrm{m}$. (C) Quantitative analysis of ED-1 positive cells at the edge of the hematoma 10 days after ICH in cells $/ \mathrm{mm}^{2} . n=4$ for the $\mathrm{ICH}$ only group, $n=3$ for the Asp group, $n=3$ for the saline group, and $n=5$ for the SAP group. ${ }^{*} \mathrm{P}<0.05$ versus the other groups. Asp: aspiration only. 
A
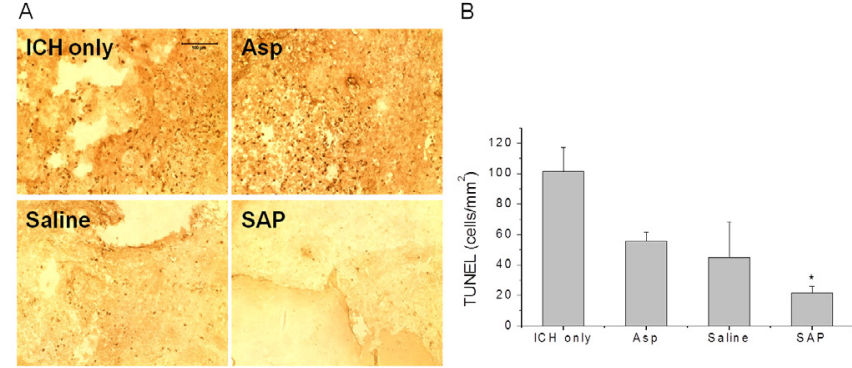

Figure 6: Apoptosis 3 days after $\mathrm{ICH}$. (A) Representative images showed TUNEL positive cells at the edge of the hematoma. (B) Quantitative analysis of TUNEL positive cells at the edge of the hematoma. $n=4$ per group. ${ }^{*} P<$ 0.05 versus the other groups. Scale bar $=100 \mu \mathrm{m}$. Aap: aspiration only.
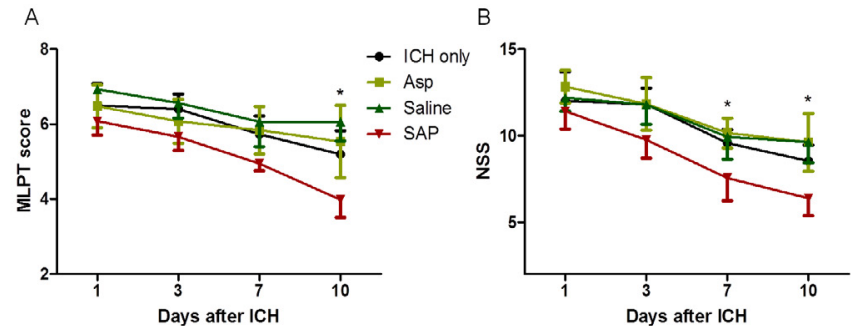

Figure 7: (A) MLPT score 1, 3, 7, 10 days after ICH. (B) NSS 1, 3, 7, and 10 days after $\mathrm{ICH} . \mathrm{n}=5$ for the SAP group, $\mathrm{n}=6$ for the $\mathrm{ICH}$ only group, $\mathrm{n}=5$ for the Asp group, and $n=5$ for the saline group. ${ }^{*} P<0.05$ versus the other groups. Asp: aspiration only.

group, $9.6 \pm 1.2$ ).

\section{Discussion}

In this study, combining minimally invasive hematoma aspiration with local delivery of SAPNS attenuated acute brain injury and enhanced functional recovery in a rat model of hypertensive ICH. These effects were associated with the prevention of hematoma growth as well as reduction of brain edema, perihematomal apoptosis and inflammatory reaction.

Hypertension is the single most important risk factor for spontaneous ICH [27-31]. Our previous study showed the SBP of the RVHT rats increased gradually and became stable around levels of 160$190 \mathrm{mmHg}$ at 6 weeks after unilateral renal artery constriction [12]. No spontaneous stroke was seen in the RVHT rats within the study period. This rat model of hypertensive ICH closely mimics ICH patient with elevated BP. Using this model, the present study evaluated the effects of a hemostatic nanomaterial on the $\mathrm{ICH}$-induced brain injury. In consistent with previous studies on open surgical sites [11], local delivery of SAPNS prevented the hematoma growth in the deep brain in the hypertensive rats.

RADA16-I peptide, the SAP used in this study, is composed of repeated sequence of arginine, alanine, aspartate and alanine. A unique characteristic of the RADA16-I is its ability to self-assemble into a nanofiber scaffold upon contact with cations [32]. It can fit into an irregular space and assembly into a scaffold within seconds. Our previous study showed that in normotensive rats, SAPNS replaced deep brain hematoma, reduced the brain cavity formation [ref. in press]. The SAP has also been shown to achieve hemostasis when applied to open bleeding sites [11]. Our previous study showed that hypertension aggravated $\mathrm{ICH}$-related brain injury and deficits in the rat [12]. Moreover, stereotactic aspiration of blood led to decompression of brain tissue in these normotensive rats [13]. In the present study, the RADA16-I SAP solution could fill in brain cavity created by hematoma aspiration and, more importantly, it could stop hematoma growth in the hypertensive rats. The present results revealed for the first time that intracerebral administration of SAP solution following hematoma aspiration during the hyperacute stage of ICH exhibited hemostatic effect. In addition, the building blocks of RADA16-I are made of pure natural $\mathrm{L}$-amino acids. The amino acids generated from degradation of RADA16-I can be utilized as an additional source of amino acids, and toxic effects of the SAP solution was not seen in various animal models $[8,9,33]$.

Brain edema and inflammation are important mechanisms underlying ICH-associated brain injury $[9,21,26,34]$. Brain swelling due to edema is a marker for tissue damage [35] and a key contributor to raised intracranial pressure (ICP) [36]. High ICP reduces cerebral perfusion pressure [37] and causes brain ischemia, herniation, and/ or brain death $[35,37,38]$. Blood breakdown products may contain high concentrations of detrimental factors, such as iron and thrombin [39]. Free iron may mount a free radical-mediated damage of the endothelium and aggravate blood-brain-barrier (BBB) dysfunction $[40,41]$. Reduction of iron release from lysed red blood cells is associated with reduced brain edema [42].Thrombin mediates a detrimental role via activation of the inflammatory cascade [43-48]. Firstly, it activates the inflammatory cascade via chemotaxis of leukocytes, expression of adhesion molecules, and release of inflammatory cytokines. Secondly, thrombin enhances expression of matrix metalloproteinases, which can break down BBB and cause edema formation [49]. Inflammation and brain edema were reduced in the SAP treatment group. Possible explanations include the followings. Decreased hematoma volume is associated with reduced amount of toxic blood breakdown products and less inflammatory cytokines/chemotactic factors. In addition, these detrimental mediators may diffuse into the SAPNS and therefore their concentrations in the perihematomal area are reduced.

Although ICH patients have a high mortality rate of $31 \% 7$ days after onset [50,51], the mortality rate was zero within 10 days after experimental ICH in the hypertensive rats in this study because we used a low dose of collagenase IV $(0.12 \mathrm{U})$ to induce the ICH. Intrastriatal injection of $0.12 \mathrm{U}$ of collagenase IV in RVHT rats would produce a relative small hematoma not extending to the lateral ventricle, and the aspiration procedure was successful without noting CSF in the aspirated liquid. Despite zero mortality rate, severe sensorimotor deficits were seen in all the groups of hypertensive rats. The reduced hematoma volume in the SAP treatment group could have limited the secondary brain damage and accounted for the improved functional recovery. Future studies may be conducted to examine the survival of surrounding neuronal cells, endogenous neurogenesis and repair of brain circuits within and around the lesion site.

In conclusion, we applied a nanomaterial into the deep brain cavity immediately after hematoma aspiration in a rat model of hypertensive $\mathrm{ICH}$. Our results suggest that the SAP can serve as a biocompatible material, reduce acute brain injury, and improve functional recovery. The present study therefore provides some evidence for the potential application of SAPNS in patients with hypertensive ICH.

\section{Acknowledgement}

This work was supported by the General Research Fund of the Research 
Citation: Sang LY, Liang YX, So KF, Leung GK, Ellis-Behnke RG, et al. (2014) A Self-assembling Nanomaterial Reduces Acute Brain Injury and Enhances Functional Recovery in a Rat Model of Hypertensive Intracerebral Hemorrhage. J Nanomed Nanotechnol 5: 224. doi: $10.4172 / 2157-7439.1000224$

Page 6 of 7

Grants Council (HKU763109M), the Committee on Research and Conference Grants (201007176091) and the Stanley Ho Alumni Challenge Funds (208040030, 207051026).

\section{References}

1. Mayer SA, Rincon F (2005) Treatment of intracerebral haemorrhage. Lancet Neurol 4: 662-672.

2. Bath P, Chalmers J, Powers W, Beilin L, Davis S, et al. (2003) International Society of Hypertension (ISH): statement on the management of blood pressure in acute stroke. J Hypertens 21: 665-672.

3. Qureshi Al (2008) Acute hypertensive response in patients with stroke: pathophysiology and management. Circulation 118: 176-187.

4. Brott T, Broderick J, Kothari R, Barsan W, Tomsick T, et al. (1997) Early hemorrhage growth in patients with intracerebralhemorrhage. Stroke 28: 1-5.

5. Fujii Y, Takeuchi S, Sasaki O, Minakawa T, Tanaka R (1998) Multivariate analysis of predictors of hematoma enlargement in spontaneous intracerebral hemorrhage. Stroke 29: 1160-1166.

6. Fujii Y, Tanaka R, Takeuchi S, Koike T, Minakawa T, et al. (1994) Hematoma enlargement in spontaneous intracerebral hemorrhage. J Neurosurg 80: 5157.

7. Kazui S,Naritomi H, Yamamoto H, Sawada T, Yamaguchi T (1996) Enlargement of spontaneous intracerebral hemorrhage. Incidence and time course. Stroke 27: $1783-1787$

8. Schneider A,Garlick JA, Egles C (2008) Self-assembling peptide nanofiber scaffolds accelerate wound healing. PLoS One 3: e1410.

9. Ellis-Behnke RG, Liang YX, You SW, Tay DK, Zhang S, et al. (2006) Nano neuro knitting: peptide nanofiber scaffold for brain repair and axon regeneration with functional return of vision. ProcNatlAcadSci U S A 103: 5054-5059.

10. Sang LY, Liang YX, Li Y, Wong WM, Tay DK, et al. (2014) A self-assembling nanomaterial reduces acute brain injury and enhances functional recovery in a rat model of intracerebralhemorrhage. Nanomedicine

11. Ellis-Behnke RG, Liang YX, Tay DK, Kau PW, Schneider GE, et al. (2006) Nano hemostat solution: immediate hemostasis at the nanoscale. Nanomedicine 2 207-215

12. Sang YH, Su HX, Wu WT, So KF, Cheung RT (2011) Elevated blood pressure aggravates intracerebral hemorrhage-induced brain injury. J Neurotrauma 28 : 2523-2534.

13. Sang YH, Liang YX, Liu LG, Ellis-Behnke RG, Wu WT, et al. (2013) Rat model of intracerebral hemorrhage permitting hematoma aspiration plus intralesional injection. ExpAnim 62: 63-69.

14. Leenen FH, de Jong W (1971) A solid silver clip for induction of predictable levels of renal hypertension in the rat. J ApplPhysiol 31: 142-144.

15. Zeng J, Zhang Y, Mo J, Su Z, Huang R (1998) Two-kidney, two clip renovascular hypertensive rats can be used as stroke-prone rats. Stroke 29: 1708-1713.

16. Kurtz TW, Griffin KA, Bidani AK, Davisson RL, Hall JE (2005) Recommendations for blood pressure measurement in animals - summary of an aha scientific statement from the council on high blood pressure research, professional and public education subcommittee. Arteriosclerosis Thrombosis and Vascular Biology 25: 478-479.

17. Park HK, Chu K, Lee ST, Jung KH, Kim EH, et al. (2005) Granulocyte colonystimulating factor induces sensorimotor recovery in intracerebral hemorrhage. Brain Res 1041: 125-131.

18. Matsushita K, Meng W, Wang X, Asahi M, Asahi K, et al. (2000) Evidence for apoptosis after intercerebral hemorrhage in rat striatum. J Cereb Blood Flow Metab 20: 396-404.

19. Auriat A,Plahta WC, McGie SC, Yan R, Colbourne F (2005) 17 beta-Estradiol pretreatment reduces bleeding and brain injury after intracerebral hemorrhagic stroke in male rats. J Cereb Blood Flow Metab 25: 247-256.

20. Sgonc R,Boeck G, Dietrich H, Gruber J, Recheis H, et al. (1994) Simultaneous determination of cell surface antigens and apoptosis. Trends Genet 10: 41-42.

21. Chu K, Jeong SW, Jung KH, Han SY, Lee ST, et al. (2004) Celecoxib induces functional recovery after intracerebral hemorrhage with reduction of brain edema and perihematomal cell death. J Cereb Blood Flow Metab 24: 926-933.

22. Jung KH, Chu K, Jeong SW, Han SY, Lee ST, et al. (2004) HMG-CoA reductase inhibitor, atorvastatin, promotes sensorimotor recovery, suppressing acute inflammatory reaction after experimental intracerebral hemorrhage. Stroke 35 1744-1749.

23. Lee ST, Chu K, Sinn DI, Jung KH, Kim EH, et al. (2006) Erythropoietin reduces perihematomal inflammation and cell death with eNOS and STAT3 activations in experimental intracerebral hemorrhage. J Neurochem 96: 1728-1739.

24. Song EC, Chu K, Jeong SW, Jung KH, Kim SH, et al. (2003) Hyperglycemia exacerbates brain edema and perihematomal cell death after intracerebral hemorrhage. Stroke 34: 2215-2220.

25. Chen J, Li Y, Wang L, Zhang Z, Lu D, et al. (2001) Therapeutic benefit of intravenous administration of bone marrow stromal cells after cerebral ischemia in rats. Stroke 32: 1005-1011.

26. Narantuya D, Nagai A, Sheikh AM, Masuda J, Kobayashi S, et al. (2010) Human microglia transplanted in rat focal ischemia brain induceneuroprotection and behavioral improvement. PLoS One 5: e11746.

27. Qureshi AI,Suri MA, Safdar K, Ottenlips JR, Janssen RS, et al. (1997) Intracerebral hemorrhage in blacks. Risk factors, subtypes, and outcome. Stroke 28: 961-964.

28. [No authors listed] (1998) Blood pressure, cholesterol, and stroke in eastern Asia. Eastern Stroke and Coronary Heart Disease Collaborative Research Group. Lancet 352: 1801-1807.

29. Ariesen MJ, Claus SP, Rinkel GJ, Algra A (2003) Risk factors for intracerebral hemorrhage in the general population: a systematic review. Stroke 34: 20602065.

30. Zia E, Pessah-Rasmussen H, Khan FA, Norrving B, Janzon L, et al. (2006) Risk factors for primary intracerebral hemorrhage: a population-based nested casecontrol study. Cerebrovasc Dis 21: 18-25.

31. Brott $T$, Thalinger K, Hertzberg $V$ (1986) Hypertension as a risk factor for spontaneous intracerebral hemorrhage. Stroke 17: 1078-1083.

32. Davis ME, Motion JP, Narmoneva DA, Takahashi T, Hakuno D, et al. (2005) Injectable self-assembling peptide nanofibers create intramyocardial microenvironments for endothelial cells. Circulation 111: 442-450.

33. Misawa H, Kobayashi N, Soto-Gutierrez A, Chen Y, Yoshida A, et al. (2006) PuraMatrix facilitates bone regeneration in bone defects of calvaria in mice. Cell Transplant 15: 903-910.

34. Morley EJ,Zehtabchi S (2008) Evidence-based emergency medicine/ systematic review abstract. Mannitol for traumatic brain injury: searching for the evidence. Ann Emerg Med 52: 298-300.

35. Xi G, Keep RF, Hoff JT (2006) Mechanisms of brain injury after intracerebral haemorrhage. Lancet Neurol 5: 53-63.

36. Ernest Eugene Moore DVF, Kenneth L. Mattox, Trauma 2004: McGraw-Hill, Medical Pub.

37. Moppett IK (2007) Traumatic brain injury: assessment, resuscitation and early management. Br J Anaesth 99: 18-31.

38. Ghajar J (2000) Traumatic brain injury. Lancet 356: 923-929.

39. Xi G,Reiser G, Keep RF (2003) The role of thrombin and thrombin receptors in ischemic, hemorrhagic and traumatic brain injury: deleterious or protective? J Neurochem 84: 3-9.

40. Xi G, Hua Y, Bhasin RR, Ennis SR, Keep RF, et al. (2001) Mechanisms of edema formation after intracerebral hemorrhage: effects of extravasated red blood cells on blood flow and blood-brain barrier integrity. Stroke 32: 29322938.

41. Nakamura T, Keep RF, Hua Y, Hoff JT, Xi G (2005) Oxidative DNA injury after experimental intracerebral hemorrhage. Brain Res 1039: 30-36.

42. Xi GH, Nakamura T, Keep RF, Hua Y, Schallert T, et al. (2004) Deferoxamine attenuates brain edema and neurological deficits in a rat model of intracerebral hemorrhage. Stroke 35:328-328.

43. Xi G, Keep RF, Hoff JT (1998) Erythrocytes and delayed brain edema formation following intracerebral hemorrhage in rats. J Neurosurg 89: 991-996.

44. Xi G, Hua Y, Keep RF, Younger JG, Hoff JT (2002) Brain edema after intracerebral hemorrhage: the effects of systemic complement depletion. ActaNeurochirSuppl 81: 253-256.

45. Lee KR, Kawai N, Kim S, Sagher O, Hoff JT (1997) Mechanisms of edema 
Citation: Sang LY, Liang YX, So KF, Leung GK, Ellis-Behnke RG, et al. (2014) A Self-assembling Nanomaterial Reduces Acute Brain Injury and Enhances Functional Recovery in a Rat Model of Hypertensive Intracerebral Hemorrhage. J Nanomed Nanotechnol 5: 224. doi: $10.4172 / 2157-7439.1000224$

formation after intracerebral hemorrhage: Effects of thrombin on cerebral blood flow, blood-brain barrier permeability, and cell survival in a rat model. $J$ Neurosurg 86: 272-278.

46. Xi G, Wagner KR, Keep RF, Hua Y, de Courten-Myers GM, et al. (1998) Role of blood clot formation on early edema development after experimental intracerebral hemorrhage. Stroke 29: 2580-2586.

47. Rosenberg GA, Navratil M (1997) Metalloproteinase inhibition blocks edema in intracerebral hemorrhage in the rat. Neurology 48: 921-926.

48. Gong C, Hoff JT, Keep RF (2000) Acute inflammatory reaction following experimental intracerebral hemorrhage in rat. Brain Res 871: 57-65.

49. Nishimura $T$, Itoh $T$ (1988) Higher level expression of lymphocyte functionassociated antigen-1 (LFA-1) on in vivo natural killer cells. Eur J Immunol 18 2077-2080.

50. Flaherty ML,Haverbusch M, Sekar P, Kissela B, Kleindorfer D, et al. (2006) Long-term mortality after intracerebral hemorrhage. Neurology 66: 1182-1186.

51. Fogelholm R,Murros K, Rissanen A, Avikainen S (2005) Long term survival after primary intracerebral haemorrhage: a retrospective population based study. J NeurolNeurosurg Psychiatry 76: 1534-1538. 